\title{
CCR2 modulates inflammatory and metabolic effects of high-fat feeding
}

\author{
Stuart P. Weisberg, ${ }^{1}$ Deborah Hunter, ${ }^{2}$ Reid Huber, ${ }^{2}$ Jacob Lemieux, ${ }^{1}$ Sarah Slaymaker, ${ }^{3}$ \\ Kris Vaddi, ${ }^{2}$ Israel Charo, ${ }^{3}$ Rudolph L. Leibel, ${ }^{1,4}$ and Anthony W. Ferrante Jr. ${ }^{1}$

\begin{abstract}
1Department of Medicine, Naomi Berrie Diabetes Center, Columbia University College of Physicians and Surgeons, New York, New York, USA.

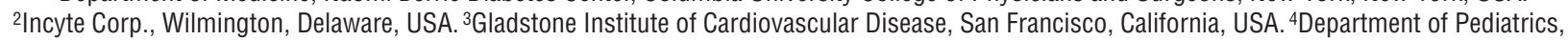
Naomi Berrie Diabetes Center, Columbia University College of Physicians and Surgeons, New York, New York, USA.
\end{abstract}

\begin{abstract}
The $\mathrm{C}-\mathrm{C}$ motif chemokine receptor-2 (CCR2) regulates monocyte and macrophage recruitment and is necessary for macrophage-dependent inflammatory responses and the development of atherosclerosis. Although adipose tissue expression and circulating concentrations of CCL2 (also known as MCP1), a high-affinity ligand for CCR2, are elevated in obesity, the role of CCR2 in metabolic disorders, including insulin resistance, hepatic steatosis, and inflammation associated with obesity, has not been studied. To determine what role CCR2 plays in the development of metabolic phenotypes, we studied the effects of $\mathrm{Cr} 2$ genotype on the development of obesity and its associated phenotypes. Genetic deficiency in $\mathrm{Ccr} 2$ reduced food intake and attenuated the development of obesity in mice fed a high-fat diet. In obese mice matched for adiposity, $\mathrm{C} c r 2$ deficiency reduced macrophage content and the inflammatory profile of adipose tissue, increased adiponectin expression, ameliorated hepatic steatosis, and improved systemic glucose homeostasis and insulin sensitivity. In mice with established obesity, short-term treatment with a pharmacological antagonist of CCR2 lowered macrophage content of adipose tissue and improved insulin sensitivity without significantly altering body mass or improving hepatic steatosis. These data suggest that CCR2 influences the development of obesity and associated adipose tissue inflammation and systemic insulin resistance and plays a role in the maintenance of adipose tissue macrophages and insulin resistance once obesity and its metabolic consequences are established.
\end{abstract}

\section{Introduction}

Obesity is associated with a complex systemic inflammatory state that has been implicated in the development of common, medically important complications, including atherosclerosis, hepatic steatosis, and insulin resistance (1-4). Characteristics of obesityinduced inflammation include elevated expression and production of proinflammatory molecules by adipose tissue, liver, and skeletal muscle (5-11); increased circulating concentrations of proinflammatory proteins, including acute-phase reactants, procoagulant factors, cytokines, and chemokines $(3,12)$; and the activation of pathways that regulate inflammation, including JNK and NF-KB pathways (10, 13-15). Obesity also induces the accumulation of macrophages in adipose tissue without altering the macrophage content of liver or muscle $(8,16)$. Macrophages produce some of the proinflammatory molecules released by adipose tissue and have been implicated in the development and maintenance of obesity-induced adipose tissue inflammation (8, $16,17)$, but the mechanisms that recruit and retain macrophages in adipose tissue remain obscure.

Monocyte chemoattractant proteins (MCPs) and their receptors play pivotal roles in the development of inflammatory responses and are crucial for the recruitment of immune cells to sites of inflammation. In obese rodents and humans, the adipose tissue expression of at least $1 \mathrm{MCP}, \mathrm{C}-\mathrm{C}$ motif chemokine ligand-2 (CCL2

Nonstandard abbreviations used: ATM, adipose tissue macrophage; CCL, chemokine, C-C motif, ligand; CCR, CCL receptor; HOMA-IR, homeostasis model assessment of insulin resistance; MCP, monocyte chemoattractant protein; PAI, plasminogen activator inhibitor; SVC, stromal vascular cell.

Conflict of interest: K. Vaddi, D. Hunter, and R. Huber are employed by Incyte Corp.

Citation for this article: J. Clin. Invest. 116:115-124 (2006).

doi:10.1172/JCI24335. or MCP1), is increased in proportion to adiposity. Both the adipose tissue expression and circulating concentrations of CCL2 increase in obesity and decrease following treatment with thiazolidinediones (18-20). Recent studies further implicate CCL2 and its receptor, CCR2, in the regulation of adipocyte function. These studies found that CCL2 inhibits insulin-stimulated glucose uptake as well as the adipocyte expression of metabolically important genes (e.g., Glut4, Pparg, and Fabp4) in a murine adipocyte cell line (21). CCR2 is a receptor for other MCPs, including CCL8 (MCP2) and CCL7 (MCP3) $(22,23)$, and is necessary for the recruitment of monocytes/ macrophages in murine models of atherosclerosis, rheumatoid arthritis, and mycobacterial infections (24).

Because CCR 2 regulates monocyte and macrophage chemotaxis and local inflammatory responses, and is implicated in regulating glucose uptake in an insulin-responsive cell line, we hypothesized that monocyte chemoattractant molecules acting through CCR2 might regulate obesity-induced inflammation in adipose tissue and associated perturbations in systemic glucose homeostasis. We studied the expression of ligands for CCR2 in lean and obese mice and in obese mice treated with a thiazolidinedione. We examined the effects of Ccr2 deficiency on development of diet-induced obesity, insulin sensitivity, adipose tissue histology, and gene expression and on the plasma concentrations of proteins implicated in the inflammatory and metabolic consequences of obesity. We also examined the metabolic phenotype of obese mice treated with a selective, CCR2 antagonist after the onset of obesity. Congenital absence of CCR2 had no measurable metabolic effect in lean animals. However, in a mouse model of diet-induced obesity, CCR2 deficiency attenuated the development of obesity, adipose tissue macrophage (ATM) accumulation, adipose tissue inflammation, and systemic insulin resistance. In mice with preexisting obesity, 


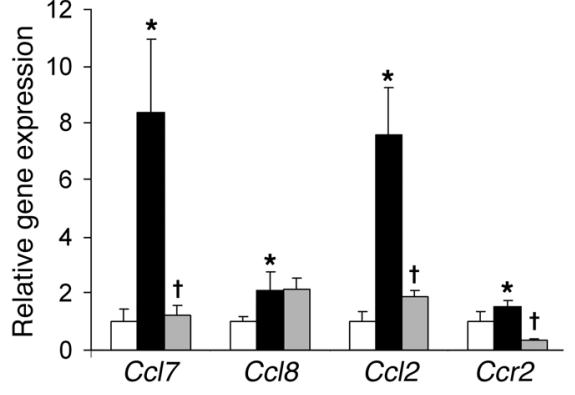

Figure 1

Expression of Ccr2 and its ligands in lean mice, obese mice, and obese mice treated with pioglitazone. Expression of $\mathrm{Ccr} 2$ and genes that encode 3 of its ligands, Cc/2, Ccl 7 and Cc/8, were measured in lean mice (white bars), obese mice (black bars), and obese mice treated with the insulin sensitizer pioglitazone (gray bars). ${ }^{*} P<0.05$, lean vs. obese; ${ }^{\dagger} P<0.05$ obese vs. obese pioglitazone-treated $(n=4)$. Values are expressed as mean \pm SD.

short-term pharmacologic antagonism of CCR2 reduced ATM content and improved in vivo insulin sensitivity. The mechanistic relationships among these diverse metabolic phenotypes is unclear, but these findings suggest that CCR2 modulates metabolic and inflammatory effects induced by a high-fat diet.

\section{Results}

Adipose tissue expression of Ccr 2 and its ligands is regulated by obesity. The macrophage content of adipose tissue is increased by obesity and reduced by administration of thiazolidinedione $(8,16,25)$. To identify potential regulators of macrophage accumulation in adipose tissue, we studied the expression profiles of epididymal adipose tissue from lean male C57BL/6J mice maintained on a low-fat diet (5\% of calories derived from fat) for 24 weeks (body mass, $28.9 \pm 2.5 \mathrm{~g}$; fasting insulin, $0.31 \pm 0.6 \mathrm{ng} / \mathrm{ml}) ; \mathrm{C} 57 \mathrm{BL} / 6 \mathrm{~J}$ mice made obese and insulin resistant on a high-fat diet ( $45 \%$ of calories derived from fat) for 24 weeks ( $45.8 \pm 4.8 \mathrm{~g} ; 2.3 \pm 0.5 \mathrm{ng} / \mathrm{ml})$; and C57BL/6J mice made obese on a high-fat diet for 22 weeks and then fed the highfat diet mixed with pioglitazone $(60 \mathrm{mg} / \mathrm{kg}$ ) for 2 additional weeks $(47.2 \pm 1.8 \mathrm{~g} ; 0.3 \pm 0.05 \mathrm{ng} / \mathrm{ml})$. The expression of Ccl2 (also known as Mcp1) is upregulated in adipose tissue of obese rodents (18) and humans $(20,26)$, but its receptor, CCR2, and the other CCR2 ligands (CCL7/MCP3 and CCL8/MCP2) have not be studied. In the adipose tissue of obese compared with lean mice, the expression of Ccl 2 was increased 7.6-fold $(P<0.01)$; $C c l 7$ was increased 8.4-fold $(P<0.01)$; and Ccl8 was increased 2.1-fold $(P<0.05)$. Treatment with pioglitazone significantly decreased the expression of $\mathrm{Ccr} 2$ $(P<0.001), C c l 2(P<0.01)$, and $C c l 7(P<0.01)$ but not $C c l 8$ (Figure $1)$. The influence of obesity and a thiazolidinedione on the expression of Ccr2 and its ligands is consistent with obesity-dependent alterations in CCR2 signaling within adipose tissue.

$\mathrm{Ccr} 2^{-1-}$ mice are partially protected from diet-induced obesity. To assess the role of CCR2 in the development of obesity and obesity-associated adipose tissue inflammation and insulin resistance, we fed either low-fat ( $5 \%$ calories derived from fat) or high-fat $(60 \%$ of calories derived from fat) diets to male Ccr2-deficient (C57BL/6J $\mathrm{Ccr2}^{-/-}$) or wild-type (C57BL/6J Ccr2 ${ }^{+/+}$) mice. Previous reports of mice fed standard chow diets had not noted any $\mathrm{Cr}$ genotypedependent effects on body mass $(27,28)$. Consistent with these reports, lean body mass, fat mass, and total body mass were not affected by $\mathrm{Ccr} 2$ genotype in mice fed the low-fat diet for 24 weeks (Figure 2). Unexpectedly, however, after 24 weeks on the high-fat diet, $\mathrm{Crr} 2^{-/-}$mice weighed $15 \%$ less than $\mathrm{Crr} 2^{+/+}$mice $(39.4 \pm 6.9 \mathrm{vs}$. $46.3 \pm 4.1 \mathrm{~g}$ [mean $\pm \mathrm{SD}] ; P<0.05)$. Even though the mean body mass of the high-fat diet-fed $\mathrm{Crr}^{-/-}$mice was lower than that of comparably fed $\mathrm{Ccr}^{+/+}$mice, most $\mathrm{Cr} 2^{-/-}$mice did in fact become obese, weighing between 40 and $50 \mathrm{~g}$, with adiposity between $40 \%$ and $50 \%$ (Figure 2A). Two-way ANOVA confirmed that both highfat diet $(P<0.001)$ and $C c r 2$ genotype $(P<0.05)$ contributed to the variation in body mass, though the genotype-diet interaction did not reach significance $(P=0.14)$. Hence, $C c r 2$ deficiency attenuated but did not prevent the development of obesity in mice fed a high-fat diet.

To better understand why $\mathrm{C} c \mathrm{r}^{-/-}$mice gained less weight while ingesting the high-fat diet, we examined food intake and body composition of individually caged $\mathrm{Ccr}^{-/-}$and $\mathrm{Ccr} 2^{+/+}$mice fed a high-fat diet for 6 weeks. Despite having similar body weights $(19.16 \pm 1.05$ g vs. $19.48 \pm 0.63 \mathrm{~g} ; P>0.05)$ and body compositions at the study's outset, $\mathrm{Cr} 2^{-/-}$mice consumed fewer kilocalories per day than $\mathrm{Ccr}^{+/+}$mice during the observation period (18.32 \pm 4.08 $\mathrm{kcal} / \mathrm{d}$ vs. $28.27 \pm 14.25 \mathrm{kcal} / \mathrm{d} ; P<0.005$; Figure $2 \mathrm{~B}$ ). At the end of the 6-week period, $\mathrm{Cr} 2^{-/-}$mice weighed significantly less than the $\mathrm{Crr} 2^{+/+}$mice $(26.96 \pm 2.20 \mathrm{~g}$ vs. $31.02 \pm 3.40 \mathrm{~g}, P<0.05$; Supplemental Figure 1; supplemental material available online with this article; doi:10.1172/JCI24335DS1); had modestly but significantly lower lean body mass $(20.86 \pm 0.69$ g vs. $22.66 \pm 1.57$ g; $P<0.05$; Supplemental Figure 1) and modestly but not significantly lower fat mass $(5.36 \pm 1.94 \mathrm{~g}$ vs. $7.82 \pm 3.36 \mathrm{~g}$; Supplemental Figure 1$)$ and adiposity $(20.06 \% \pm 5.10 \%$ vs. $25.02 \% \pm 8.36 \%$ fat $)$. These data suggest an unrecognized role for CCR2 in the regulation of feeding behavior in the context of a highly palatable diet.

Cor 2 genotype modulates insulin sensitivity in obesity. Decreased fat mass in $\mathrm{Crr} 2^{-/-}$mice fed a high-fat diet would be expected to reduce their inflammatory response and to improve systemic metabolic parameters, including insulin sensitivity. Therefore, a compari-
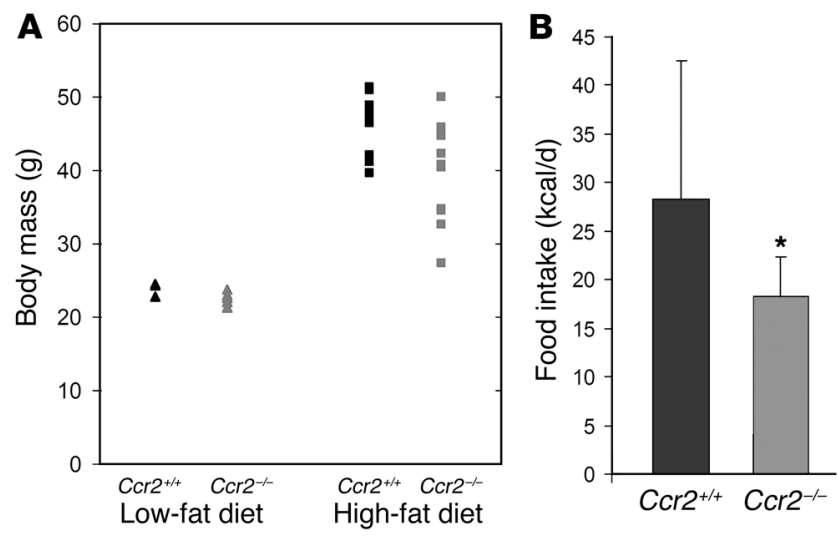

\section{Figure 2}

Body mass of $\mathrm{Ccr}^{-/-}$mice. (A) C57BL/6J Ccr2 ${ }^{+/+}$(black symbols) and $\mathrm{Ccr}^{-/-}$(gray symbols) mice were fed a low-fat (triangles) or a high-fat diet (squares) for 24 weeks. There was no significant difference in body mass between mice of each genotype on the low-fat diet $(n=5 ; P>0.05)$. The mean body mass of $\mathrm{Ccr}^{-1-}$ mice fed a high-fat diet was significantly lower than that of the $\mathrm{Ccr} 2^{+/+}$mice $(39.3 \pm 6.9 \mathrm{~g}$ vs. $46.3 \pm 4.1 \mathrm{~g} ; n=10 ; P<0.05$ ). (B) Average daily food intake was measured over a 6-week period for $\mathrm{Ccr}^{+/+}$and $\mathrm{CCr}^{-/-}$mice fed a high-fat diet. ${ }^{*} P<0.05$ vs. $\mathrm{Ccr}^{+/+}$. 
Table 1

Body compositions and plasma lipids of animals examined in this study

\begin{tabular}{|c|c|c|c|c|c|c|c|c|c|}
\hline Genotype & Diet & Treatment & $\begin{array}{l}\text { Body mass } \\
\text { (g) }\end{array}$ & $\begin{array}{l}\text { Lean mass } \\
\quad(\mathrm{g})\end{array}$ & $\begin{array}{l}\text { Fat mass } \\
(\mathrm{g})\end{array}$ & $\%$ Body fat & $\begin{array}{c}\text { Cholesterol } \\
(\mathrm{mg} / \mathrm{dl})\end{array}$ & $\begin{array}{c}\text { TGs } \\
\text { (mg/dl) }\end{array}$ & $\begin{array}{c}\text { NEFAs } \\
(\mathrm{mmol} / \mathrm{l})\end{array}$ \\
\hline Ccr2 $2^{+/+}$ & Low-fat & None & $23.8 \pm 0.88$ & $19.4 \pm 0.41$ & $3.4 \pm 0.43$ & $14.8 \pm 1.5$ & $124 \pm 59$ & $95 \pm 23$ & $2.8 \pm 0.48$ \\
\hline $\mathrm{Ccr}^{--}$ & Low-fat & None & $22.6 \pm 0.94$ & $18.6 \pm 0.80$ & $3.0 \pm 0.22$ & $13.9 \pm 0.85$ & $99 \pm 9$ & $96 \pm 20$ & $2.4 \pm 0.34$ \\
\hline Ccr2 $2^{+/+}$ & High-fat & None & $47.4 \pm 3.7$ & $27.2 \pm 2.5$ & $21.3 \pm 2.1$ & $44.0 \pm 2.8$ & $240 \pm 31$ & $71 \pm 7.4$ & $2.6 \pm 0.33$ \\
\hline Ccr2-- & High-fat & None & $45.4 \pm 5.7$ & $24.2 \pm 1.6$ & $20.5 \pm 4.1$ & $45.4 \pm 5.2$ & $201 \pm 56$ & $81 \pm 4.0^{\mathrm{A}}$ & $2.5 \pm 0.15$ \\
\hline $\mathrm{Ccr}^{+/+}$ & High-fat & INCB3344 & $46.3 \pm 3.2$ & $23.4 \pm 1.0$ & $19.7 \pm 1.6$ & $45.6 \pm 1.8$ & $272 \pm 44$ & $100 \pm 7.1$ & $2.4 \pm 0.19$ \\
\hline Ccr2 $2^{+/+}$ & High-fat & Vehicle & $46.6 \pm 2.4$ & $23.3 \pm 1.4$ & $20.7 \pm 2.2$ & $47.0 \pm 2.3$ & $227 \pm 35$ & $111 \pm 15$ & $2.3 \pm 0.37$ \\
\hline
\end{tabular}

Unselected lean and obese $\mathrm{Ccr} 2^{-/-}$and $\mathrm{Ccr} 2^{+/+}$mice matched for body mass as well as obese $\mathrm{Ccr} 2^{+/+}$mice treated with $\mathrm{CCR} 2$ antagonist or vehicle were studied. Body mass, lean mass, fat mass, and percent body fat did not differ between lean Ccr2 $2^{+/+}$and $C c r 2^{-/-}$animals. Lean body mass was slightly lower in obese Ccr2-/- compared with obese Ccr2+/+ mice $(n=10 ; P<0.05)$. Daily subcutaneous injection (17 days) of obese mice with CCR2 antagonist INCB3344 did not alter body mass, lean mass, fat mass, or percent body fat when compared with obese mice treated with vehicle. There were no significant genotype- or treatment-dependent differences in circulating fasting concentrations of lipids, except that TG concentrations were lower in plasma from obese $\mathrm{Ccr} 2^{+/+}$mice compared with obese $\mathrm{Ccr} 2^{-/-}$animals $\left({ }^{A} P<0.05\right)$. Values are expressed as mean \pm SD. NEFA, nonesterified fatty acid.

son of all high-fat diet-fed $\mathrm{Ccr} 2^{-/-}$mice with their $\mathrm{Ccr}^{+/+}$counterparts might overstate the true effect of Ccr2 genotype on ATM accumulation, adipose tissue inflammatory response, and insulin sensitivity in obese mice. To distinguish the direct effects of CCR2 deficiency on insulin sensitivity and ATM accumulation from the secondary effects of reduced weight and adiposity, we compared ATM accumulation and insulin sensitivity in mice from both highfat diet-fed groups that weighed more than $40 \mathrm{~g}$. Among these high-fat diet-fed mice, there was no significant difference in body mass, total fat mass, or percent body fat (Table 1).

We measured fasting blood glucose and plasma insulin concentrations and calculated homeostasis model assessment of insulin resistance (HOMA-IR) values in 4 groups of mice: lean $\mathrm{Ccr}^{+/+}$, lean $\mathrm{Crr}^{-/-}$, obese $\mathrm{Crr} 2^{+/+}$, and adiposity-matched obese $\mathrm{Cr} 2^{-/-}$mice. No difference was observed in the fasting blood glucose or plasma insulin concentrations between lean $\mathrm{Crr}^{-/-}$and lean $\mathrm{Ccr}^{+/+}$ mice. Likewise, there was no effect of Ccr2 genotype on insulin sensitivity (as measured by HOMA-IR) in lean animals (Figure 3). However, obese $\mathrm{Crr}^{-{ }^{--}}$mice had lower fasting blood glucose and insulin concentrations compared with adiposity-matched obese $\mathrm{Ccr} 2^{+/+}$mice (Figure 3). Consistent with increased insulin sensi- tivity, the HOMA-IR values of obese $\mathrm{Ccr}^{-/-}$mice were 50\% lower than those of equally obese $\mathrm{Ccr} 2^{+/+}$animals $\left(P<10^{-4}\right.$; Figure 3$)$. Two-way ANOVA demonstrated a significant interaction between body weight and $\mathrm{Ccr} 2$ genotype in modulating fasting glucose $(P<0.0005)$, insulin $(P<0.05)$, and HOMA-IR $(P<0.001)$.

Obese $\mathrm{Crr} 2^{-/-}$mice were also more insulin sensitive than obese $\mathrm{Ccr}^{+/+}$animals as measured by an insulin tolerance test (Figure 4). Similarly, Ccr 2 deficiency improved glucose tolerance during an intraperitoneal glucose tolerance test. Obese $\mathrm{Ccr} 2^{-/-}$mice were less hyperglycemic compared with obese $\mathrm{Ccr} 2^{+/+}$animals at 45,60 , and 90 minutes following intraperitoneal injection of a glucose bolus (Figure 4).

Cor2 deficiency attenuates obesity-induced hepatic steatosis. Hepatic insulin resistance in obese mice and humans is strongly associated with hepatomegaly and hepatic steatosis (29). To determine whether improved insulin sensitivity associated with Ccr2 deficiency ameliorated hepatomegaly or reduced hepatic steatosis, we analyzed the livers from obese $\mathrm{Crr} 2^{+/+}$and $\mathrm{Ccr} 2^{-/-}$mice. As expected, obese $\mathrm{Ccr} 2^{+/+}$ mice had a more than 10 -fold higher concentration of hepatic triglycerides (TGs) than lean $\mathrm{Ccr}^{+/+}$mice $(82.1 \pm 19.6$ vs. $7.8 \pm 2.6$ $\mathrm{mg} \mathrm{TG} / \mathrm{g}$ tissue; $P<0.001)$. Adiposity-matched obese $\mathrm{Ccr} 2^{-/-}$mice

\section{Figure 3}

Insulin sensitivity in obese $\mathrm{Ccr}^{-/-}$and obese $\mathrm{Ccr} 2^{+/+}$mice. Fasting plasma insulin (A) and blood glucose concentrations (B) were measured in lean $\mathrm{Ccr}^{+/+}$(black bars) and $\mathrm{CCr}^{-/-}$(gray bars) mice and mice of both genotypes made obese following 20 weeks of high-fat diet feeding. There were no significant genotype-dependent differences in fasting glucose or insulin concentrations in lean animals. However, fasting glucose and insulin concentrations were lower in obese $\mathrm{CCr}^{-/-}$compared with obese $\mathrm{CCr}^{+/+}$mice despite similar degrees of adiposity (insulin: $P<0.005$; glucose: $P<10^{-4}$ ). (C) HOMA-IR values (expressed as IU-mg/dl) were significantly lower $\left(P<10^{-4}\right)$ among obese $C$ Cr2 $2^{--}$than obese $\mathrm{CCr}^{+/+}$mice. (D) A plot of HOMA-IR values against body mass among all Ccr2 $2^{-/-}$(gray squares) and $\mathrm{CCr}^{+/+}$(black circles) mice reveals that the relationship between insulin sensitivity and body mass differs between mice dependent upon Ccr2 genotype. ${ }^{*} P<0.01$ compared with wild type. Values are expressed as mean \pm SD.
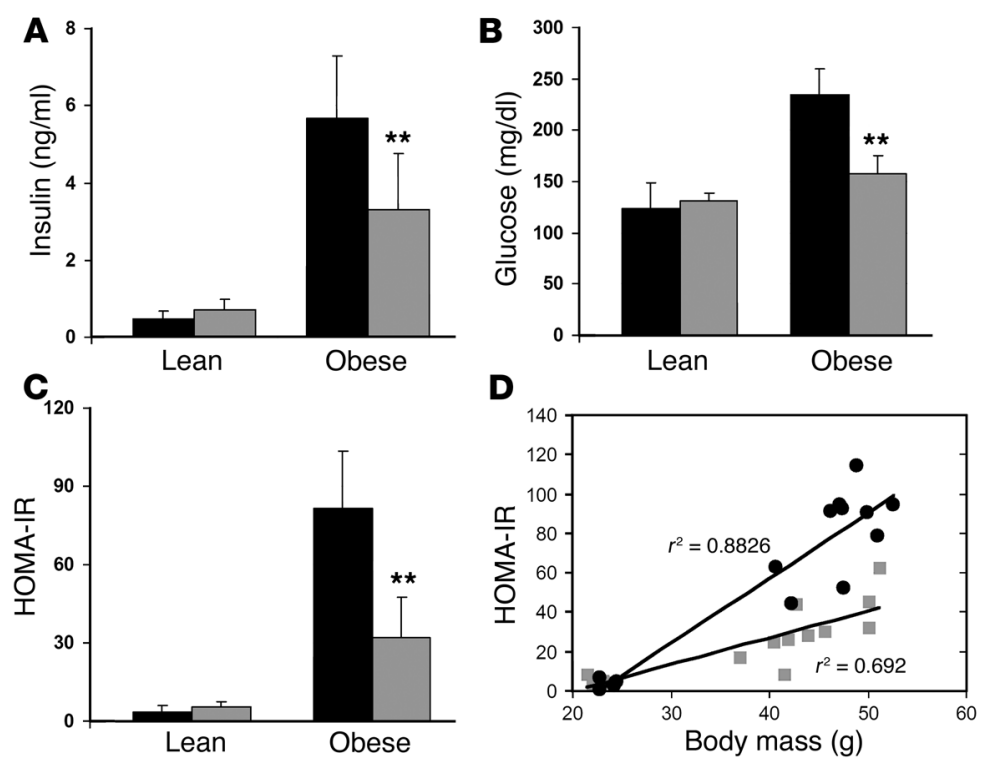

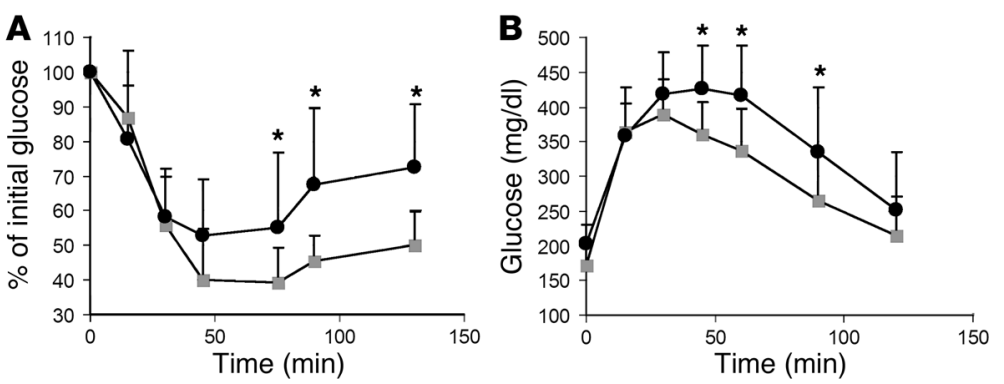

Figure 4

Glucose homeostasis in obese $\mathrm{Ccr}^{-/-}$and $\mathrm{Ccr} 2^{+/+}$mice. (A) The response of fasted obese $\mathrm{CCr}^{+/+}$(black circles) and $\mathrm{Ccr}^{-/-}$(gray squares) mice following a single intraperitoneal injection of insulin $(1.5 \mathrm{U} / \mathrm{kg}$ ) was monitored by serially measuring blood glucose concentrations. The percent reduction in glucose concentration in obese $\mathrm{Ccr}^{-/-}$mice was significantly greater than that in obese $\mathrm{Ccr}^{+/+}$mice at 75,90 , and 130 minutes ( ${ }^{*} P<0.05$ ). (B) Intraperitoneal injection of a bolus of glucose to fasted obese $\mathrm{Ccr}^{+/+}$(black circles) and $\mathrm{Ccr}^{-/-}$(gray squares) mice lead to similar peak glucose concentrations but lower glucose concentrations at 45,60 , and 90 minutes. ${ }^{*} P<0.05$ compared with wild type. Values are expressed as mean $\pm \mathrm{SD}$.

had $50 \%$ lower hepatic TG content than obese $\mathrm{Ccr} 2^{+/+}$animals (43.9 \pm 23.6 vs. $82.1 \pm 19.6 \mathrm{mg}$ TGs $/ \mathrm{g}$ tissue; $P<0.001)$. Similarly, livers of obese $\mathrm{Crr} 2^{+/+}$mice weighed $50 \%$ more than those of comparably obese $\mathrm{Ccr} 2^{-1-}$ animals $(2.4 \pm 0.5 \mathrm{~g}$ vs. $1.6 \pm 0.6 \mathrm{~g} ; P<0.001)$.

Ccr 2 deficiency decreases macrophage content of adipose tissue. In earlier mouse studies, ATM content was strongly correlated with adiposity $(8,16)$. To determine whether the accumulation of ATMs during the development of obesity is dependent upon CCR2, we compared adipocyte size and ATM content in diet-induced obese $\mathrm{Ccr}^{-/-}$and $\mathrm{Ccr} 2^{+/+}$mice that were matched for adiposity. We measured macrophage content and adipocyte morphology by immunohistochemistry in epididymal and subcutaneous adipose tissue depots obtained from obese $\mathrm{Crr}^{-/-}$and $\mathrm{Crr}^{+/+}$mice. In epididymal adipose tissue, adipocyte morphology was similar in both genotypes. However, adipocyte size (median cross-sectional area) was greater in the $\mathrm{Ccr}^{-/-}$mice (median, $4,457 \pm 650 \mu \mathrm{m}^{2}$; mean, $5,005 \pm 621 \mu^{2}$ ) compared with the obese $\mathrm{Ccr}^{+/+}$controls (median, 3,588 $\pm 561 \mu \mathrm{m}^{2}$; mean, 4,345 $\pm 460 \mu \mathrm{m}^{2} ; P<0.05$ for median). As a percentage of cells, adipose tissue from obese $\mathrm{Ccr} 2^{+/+}$mice contained more ATMs $(25 \% \pm 5.6 \%)$ than that from lean $\mathrm{Ccr}^{+/+}$ animals $(7.2 \% \pm 4.9 \%)$. However, despite having adipocytes that were larger and total adiposity that was equal, the ATM content of epididymal adipose tissue in obese $\mathrm{Ccr}^{-/-}(16.3 \% \pm 3 \%)$ mice was significantly less than the ATM content of adipose tissue in obese

\section{Figure 5}

CCR2 deficiency lowers ATM content in obese mice. The fraction of F4/80-expressing macrophages was determined by immunohistochemical analysis of epididymal adipose tissue from obese $\mathrm{Ccr}^{+/+}(\mathbf{A})$ and $\mathrm{Ccr}^{-1-}$ (B) mice with the macrophage-specific marker F4/80 (EMR1). (C) The fraction of ATMs (F4/80-stained cells/ total cells) in periepididymal adipose tissue of obese $\mathrm{Ccr}^{+/+}$mice (white bar) was significantly greater than the fraction of ATMs in lean Ccr2 $2^{+/+}$mice (black bar) $\left(P<10^{-4}\right)$ and obese $C c r 2^{-/-}$mice (gray bar) $(P<0.005)$. (D) The average fraction of ATMs was also greater in subcutaneous adipose tissue of obese $\mathrm{Ccr}^{+/+}$mice (black bar) compared with obese $\mathrm{Ccr}^{-/-}$mice (gray bar). Values are expressed as mean $\pm \mathrm{SD}$. ${ }^{* *} P<0.01$ compared with obese $\mathrm{Ccr} 2^{+/+}$mice.
$\mathrm{Ccr}^{+/+}$mice $(25 \% \pm 5.6 \% ; P<0.005)$ (Figure 5). A similar reduction in macrophage content was also detected in subcutaneous adipose tissue depots (Figure 5)

Flow cytometry can also be used to isolate and quantify the fraction of ATMs that comprises stromal vascular cells (SVCs) of adipose tissue. However, a portion of ATMs is not isolated in the SVCs in standard protocols because of increased buoyancy of lipid-laden ATMs from obese animals and adherence of ATMs to adipocytes $(8,16)$. Nevertheless, characterization of SVC populations by flow cytometry has also shown a consistent increase in the fraction of ATMs in adipose tissue from obese compared with lean mice $(8,16)$. Flow cytometry, therefore, provides an alternative means of determining the relative abundance of ATMs. Using flow cytometry, we quantified the macrophage populations $\left(\mathrm{F} 4 / 80^{+}, \mathrm{Cd} 11 \mathrm{~b}^{+}\right)$in SVCs of peri-renal adipose tissue from lean $\mathrm{Crr}^{+/+}$mice and obese $\mathrm{Cr} 2^{-/-}$and $\mathrm{Crr}^{+/+}$ mice. Consistent with our immunohistochemical analysis, we found that the proportion of macrophages in SVCs isolated from obese wild-type mice $(17.6 \% \pm 5 \%$ of SVCs) was significantly greater than the proportion in the SVCs isolated from lean $\mathrm{Ccr}^{+/+}$mice $(8.1 \% \pm 2.9 \%)$ and obese $\mathrm{Cr} 2^{-/-}$mice $\left(9.4 \% \pm 1.7 \% ; P<0.001\right.$ vs. obese $\left.\mathrm{Ccr} 2^{+/+}\right)$. Thus, in obese animals, intraabdominal and subcutaneous adipose tissue depots have fewer macrophages in Ccr2-deficient mice than in adiposity-matched wild-type animals. However, Cor 2 deficiency does not normalize ATM content to that observed in lean animals, indicating that macrophage accumulation is modulated by CCR2independent factors as well.

Ccr 2 deficiency attenuates obesity-induced changes in adipose tissue gene expression. The development of obesity and insulin resistance is associated with stereotypical changes in adipose tissue expression of inflammatory and metabolic genes. Increased expression of genes that encode proinflammatory and macrophage-associated proteins is a hallmark of adipose tissue from obese animals and humans (30). To assess the role of Ccr2 in mediating the transcriptional inflammatory response to obesity, we compared the expression of genes encoding proinflammatory and macrophage marker proteins in epididymal adipose tissue from lean and obese $\mathrm{Ccr}^{+/+}$

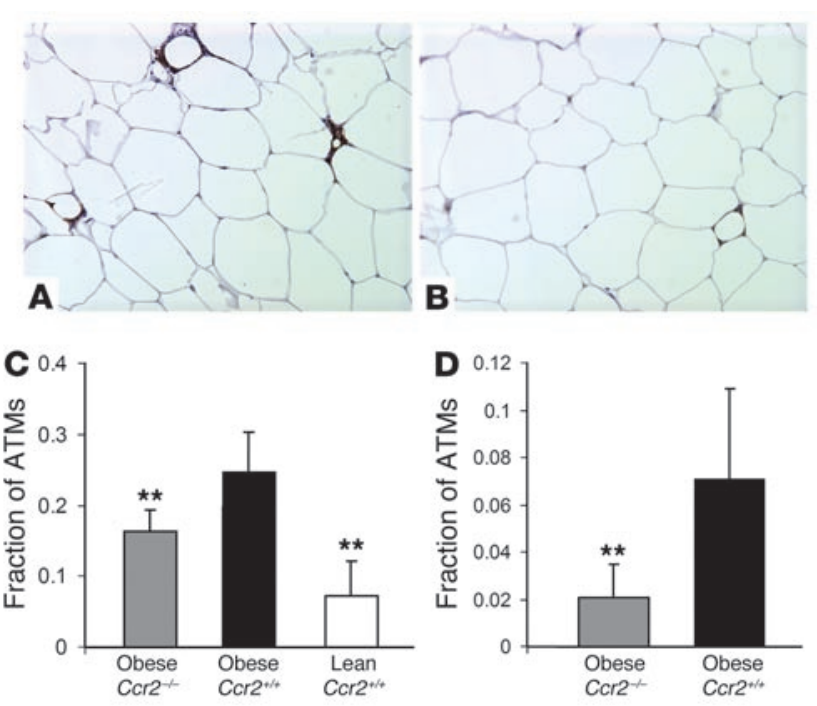




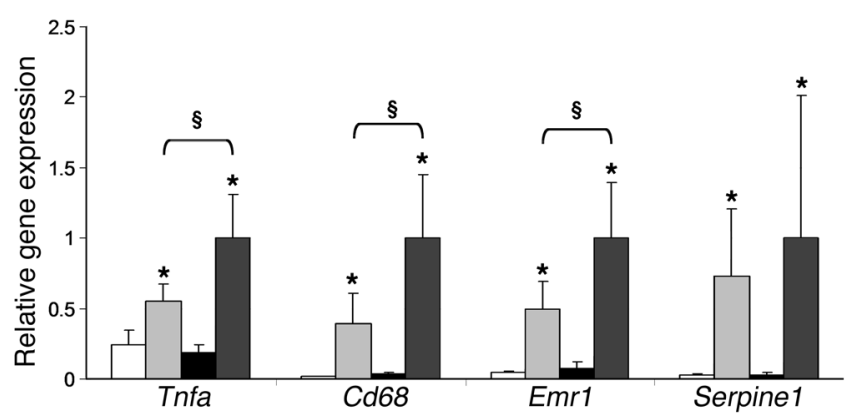

Figure 6

Expression of genes involved in inflammation. Quantitative RT-PCR was used to measure the expression in periepididymal adipose tissue of genes involved in macrophage function and inflammation (Tnfa, Cd68, Emr1, and Serpine1). Obese Ccr2 ${ }^{-/-}$(light gray bars) and obese Ccr2 $2^{+/+}$ (dark gray bars) mice with body mass greater than $40 \mathrm{~g}$ were studied, as were lean $\mathrm{Ccr}^{+/+}$mice (black bars) and lean $\mathrm{Ccr}^{-/-}$mice (white bars). ${ }^{*} P<0.05$, obese mice on high-fat chow compared with mice of the same genotype on low-fat chow; $\$ P<0.05$, obese $C c r 2^{+/+}$compared with obese $\mathrm{CCr}^{-1-}$ mice. Values are expressed as mean \pm SEM.

and $\mathrm{Cr} 2^{-/-}$mice. As expected, obese $\mathrm{Crr} 2^{+/+}$mice compared with lean $\mathrm{Ccr} 2^{+/+}$mice showed increased expression of genes encoding proinflammatory molecules including $\operatorname{Tnfa}(\mathrm{TNF}-\alpha)$ and Serpine 1 (plasminogen activator inhibitor-1 [PAI-1]) and the macrophage markers Emr1 (F4/80) and Cd68 (CD68). Consistent with the histological data, expression of the macrophage markers Emr1 and Cd68 was reduced in obese $\mathrm{Crr} 2^{-/-}$mice compared with obese $\mathrm{Cr} 2^{+/+}$ mice. By 2-way ANOVA, the variation in the expression of these genes was attributable to a significant interaction between diet and $C c r 2$ genotype (Figure 6; ANOVA interaction $P<0.05$ ). Paralleling the decrease in macrophage-specific gene expression, Tnfa expression was reduced in obese $\mathrm{C} c 2^{-1-}$ mice (Figure 6; ANOVA interaction $P<0.005)$. No significant differences in the expression of these genes were observed between lean $\mathrm{Ccr}^{-/-}$and $\mathrm{Ccr}^{+/+}$mice (Figure 6), nor were differences observed in Serpine1, Ccl2, or Ccl7 expression between obese $\mathrm{Cr} 2^{-/-}$and $\mathrm{Crr}^{+/+}$mice (data not shown). In contrast to the alterations in Tnfa expression in adipose tissue, we were consistently unable to detect circulating TNF- $\alpha$ protein $(<3.2 \mathrm{pg} / \mathrm{ml})$ in mice of either genotype or level of adiposity (data not shown). These data suggest that the local proinflammatory changes that occur in adipose tissue during the development of obesity are, in part, CCR2 dependent.

Concomitant with an increase in inflammatory gene expression, obesity leads to decreased expression of genes required for mitochondrial function, TG metabolism, and adipocyte differentiation $(8,31-33)$. Recent studies suggested that CCL2 directly effects similar changes in adipocyte gene expression (21). We measured the expression of 4 genes downregulated in obesity and by Ccl 2 treatment of adipocytes: a nuclear encoded mitochondrial gene (Gpam) $(8,32)$, a lipase (Lipe) $(8,31)$, a fatty acid binding protein (Fabp4) (32), and a transcription factor required for adipocyte differentiation (Pparg) (32). In lean animals there was no effect of Ccr2 genotype on the expression of these genes, but in obese mice the expression of these genes was increased in $\mathrm{Ccr}^{-/-}$compared with $\mathrm{Cr} 2^{+/+}$mice (Figure 7).

The effects of Cor 2 genotype on the expression of this select group of inflammatory and metabolic genes suggested that obesity-induced alterations in adipose tissue gene expression are, in part, CCR2 dependent. To more fully define the alterations in gene expression associated with Cor2 deficiency in adipose tissue of obese mice, we used oligonucleotide microarrays to compare the expression profiles of epididymal adipose tissue from $\mathrm{Crr2}^{-/-}$and $\mathrm{Crr}^{+/+}$mice with dietary obesity. Using an algorithm that identifies predefined functional classes (based on the Gene Ontology [GO] Group gene classification scheme; http://geneontology.org) of coregulated genes, we found that 71 classes of genes were significantly downregulated $(P<0.001$, corrected for multiple testing) (34). Forty-one of the downregulated groups represent inflammatory functional classes and include classes of genes involved in the regulation of immune responses (GO:0050778), interleukin receptor activity (GO:0004907), and NF-KB signaling (GO:0043122) (Supplemental Table 1). These data suggest that the inflammatory profile of adipose tissue in obese mice is broadly attenuated by deficiency of CCR2. We also found that 52 classes of genes were significantly upregulated in $\mathrm{Ccr} 2^{-/-}$compared with $\mathrm{Ccr}^{+/+}$obese mice. Consistent with the relative normalization in metabolic gene expression and with the increase in expression of Gpam, Lipe, and Glut4, 23 of the upregulated functional classes in obese $\mathrm{Crr}^{-/-}$adipose tissue are involved in intermediary metabolism, most notably mitochondria and peroxisome function, and lipid metabolism (Supplemental Table 2).

Ccr2-dependent regulation of expression and circulating concentrations of adipose tissue-derived molecules. The microarray dataset also revealed that several individual genes with higher levels of expression in $\mathrm{Cr} 2^{-/-}$than in $\mathrm{Ccr}^{+/+}$obese mice encode hormones produced by adipocytes - including leptin (Lep) $(P<0.05)$, resistin $($ Retn $)(P<0.05)$, and adiponectin $(A c d c)(P<0.05)$. Perturbations of each of these hormones has been implicated in the development of insulin resistance. Leptin deficiency leads to a syndrome of severe obesity and insulin resistance; elevation of circulating resistin is implicated in obesity-induced insulin resistance; and, conversely, decreases in the antiinflammatory and insulin-sensitizing protein adiponectin (encoded by $A c d c$ ), lead to the development of obesity-induced insulin resistance and hepatic steatosis $(35,36)$. Despite alterations in adipose tissue gene expression, we did not detect any differences in circulating concentrations

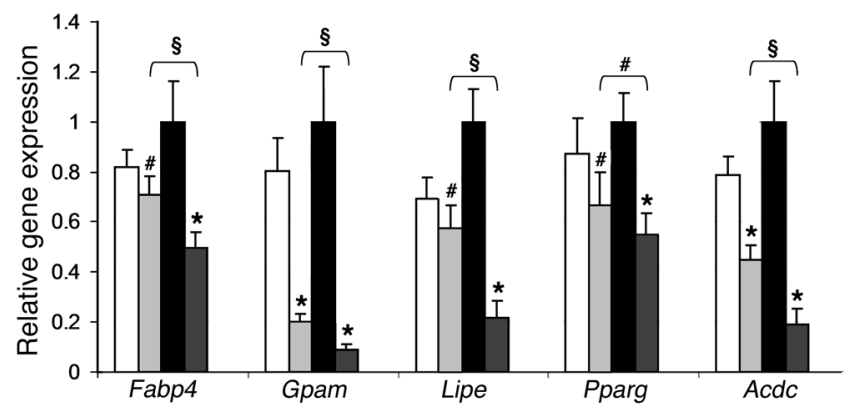

Figure 7

Expression of genes involved in adipocyte function. Quantitative RT-PCR was used to measure the expression in periepididymal adipose tissue of genes involved in adipocyte function (Fabp4, Gpam, Lipe, Pparg, and Acdc). Obese Ccr2-- (light gray bars) and obese $\mathrm{CCr}^{+/+}$(dark gray bars) mice with body mass greater than $40 \mathrm{~g}$ were studied, as were lean $\mathrm{Ccr}^{+/+}$mice (black bars) and lean $\mathrm{Ccr}^{-/-}$mice (white bars). ${ }^{*} P<0.05$, mice with dietary obesity compared with lean mice of the same genotype; $\$ P<0.05$, obese $C c r 2^{+/+}$compared with obese $\mathrm{Ccr}^{-/}$mice. \#NS. Values are expressed as mean \pm SEM. 


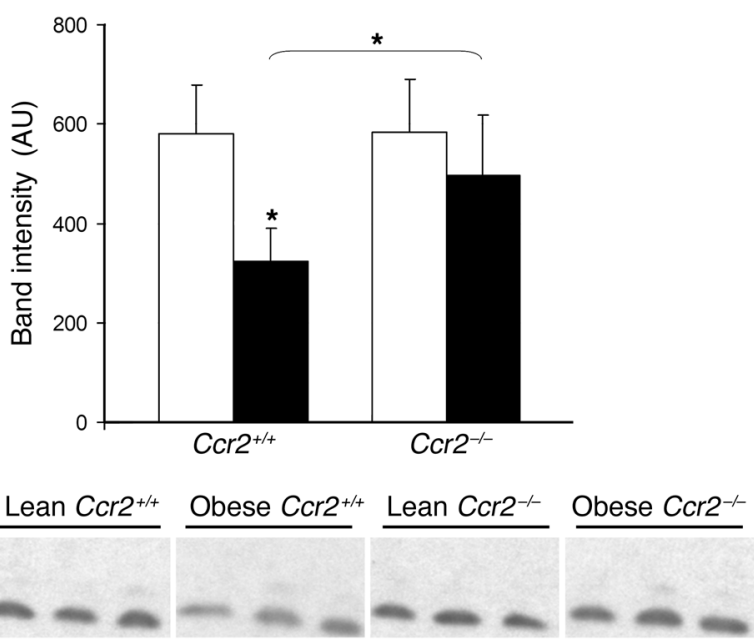

Figure 8

Plasma adiponectin in lean and obese $\mathrm{Ccr}^{-/-}$and $\mathrm{Ccr} 2^{+/+}$mice. Proteins in $1 \mu \mathrm{l}$ of plasma drawn from lean (white bars) and adipositymatched obese (black bars) $\mathrm{Ccr}^{-/-}$and $\mathrm{Ccr}^{+/+}$mice were denatured, reduced, and separated using SDS-PAGE. We performed immunoblotting for adiponectin with an antibody specific for adiponectin. Values are expressed as mean $\pm \mathrm{SD}$. ${ }^{*} P<0.05$.

of leptin or resistin between obese $\mathrm{Crr}^{-/-}$and $\mathrm{Crr}^{+/+}$mice (Supplemental Table 3). We confirmed adipose tissue gene expression of adiponectin by quantitative PCR and found, as expected, decreased expression of adiponectin in obese compared with lean $\mathrm{Ccr}^{+/+}$mice. No difference in adipose tissue $A c d c$ expression was detected between lean $\mathrm{Crr}^{+/+}$and $\mathrm{Crr}^{-/-}$animals. However, consistent with their increased systemic insulin sensitivity, adiponectin gene expression was higher in obese $\mathrm{Ccr}^{-/-}$mice compared with obese $\mathrm{Ccr}^{+/+}$animals (Figure 7). Furthermore, the amount of circulating adiponectin in plasma, while similar in lean mice of both genotypes, was significantly higher in obese mice deficient in Ccr2 than in wild-type obese animals (Figure 8).

IL- 6 and PAI- 1 are circulating proteins that are produced by multiple organs and tissues including adipose tissue, liver, leukocytes, and endothelial cells. Both have been implicated in obesity-induced insulin resistance, and the adipose tissue expression of both is increased in obesity $(18,26,37-40)$. We did not detect Ccr2-dependent modulation in adipose tissue expression of IL-6 or PAI-1. Consistent with the gene expression data, there were no CCR2-dependent alterations in the circulating concentration of IL-6. In contrast, we detected lower circulating concentrations of PAI-1 in lean and obese $\mathrm{Crr} 2^{-/-}$mice when compared with weightmatched $\mathrm{Crr}^{+/+}$mice (Supplemental Table 3). These data reveal that CCR 2 modulates circulating PAI-1 by a mechanism that is not primarily dependent upon adipose tissue expression or the development of obesity.

Effects of Ccr2 genotype on plasma lipid concentrations. In rodents and humans, obesity is associated with a dyslipidemia characterized by elevated serum concentrations of cholesterol $(41,42)$. As expected, fasting total plasma cholesterol concentrations were higher in obese compared with lean $\mathrm{Cr} 2^{+/+}$mice. In obese $\mathrm{Crr}^{-/-}$mice, the increase was similar, and there were no genotype-dependent differences between fasting cholesterols of adiposity-matched mice (Table 1). Fasting plasma concentrations of TGs and nonesterified fatty acids were not different between lean and obese animals.
No genotype-dependent effects on plasma nonesterified fatty acid (NEFA) concentrations were detected. TG concentrations were modestly higher in obese $\mathrm{Cr} 2^{-/-}$mice compared with obese $\mathrm{Ccr} 2^{+/+}$ mice (Table 1), though still lower than TG concentrations in lean mice. In contrast to other metabolic phenotypes examined, Ccr2 deficiency did not significantly reverse the lipid abnormalities associated with obesity.

Short-term treatment with a CCR2 antagonist reduces ATM content and improves insulin sensitivity in obese mice. CCR2 has been identified as a potential therapeutic target in several inflammatory disorders, including rheumatoid arthritis and multiple sclerosis. INCB3344 (Incyte Corp.) was developed as a selective small molecule antagonist of CCR2. Previous studies characterized the pharmacokinetic and pharmacodynamic profile of this molecule and demonstrated that with a single daily subcutaneous dose (100 $\mathrm{mg} / \mathrm{kg}$ ), a significant inhibition (>50\%) of murine CCR2 receptor activity is achieved in vivo (11). To test whether short-term treatment with a CCR 2 antagonist reverses any of the obesity-induced effects that are prevented in CCR2-deficient animals, we treated C57BL/6J mice made obese by feeding a high-fat diet with daily subcutaneous injections of INCB3344 $(100 \mathrm{mg} / \mathrm{kg})$ for 17 days. At the end of the treatment period, body mass and composition were not significantly different between INCB3344- and vehicletreated animals (Table 1 ).

Following 2 weeks of treatment with INCB3344, we assessed glucose homeostasis in the INCB3344-treated and vehicle-treated obese animals. After a 6-hour fast, animals receiving INCB3344 were significantly less hyperglycemic than animals receiving injections of vehicle $(143 \pm 29 \mathrm{mg} / \mathrm{dl}$ vs. $181 \pm 31 \mathrm{mg} / \mathrm{dl} ; P<0.05$; Figure $9)$. After an overnight fast (14 hours), blood glucose concentrations in the 2 groups of animals were similar. However, fasting plasma insulin concentrations were approximately 33\% lower in INCB3344-treated compared with control animals $(P<0.05)$; hence, insulin sensitivity as measured by HOMA-IR was improved $(8.3 \pm 2.5$ vs. $13.5 \pm 4.4$ IR units; $P<0.05$; Figure 9$)$. Consistent with improved insulin sensitivity, an intraperitoneal injection of insulin lowered blood glucose concentrations more in INCB3344-treated than in vehicle-injected control obese mice (Figure 9). Similar to the effects of $\mathrm{Cr} 2$ deficiency, INCB3344 treatment also improved glucose homeostasis following a glucose tolerance test (Figure 9). Treatment of obese mice with INCB3344 increased adipose tissue expression of adiponectin by $29.8 \%(P<0.05)$, although the increase in circulating adiponectin concentration did not reach statistical significance $(P>0.05)$.

We also examined the effect of CCR2 inhibition with INCB3344 on the ATM content of periepididymal adipose tissue in wildtype mice with established obesity. Immunohistochemical analysis showed a modest but significant decrease in the fraction of F4/80-expressing ATMs in obese mice that had been treated with INCB3344 (21.8\% vs. 15.7\%, vehicle- vs. INCB3344-treated; $P<0.05)$. These data implicate CCR2-dependent pathways in the maintenance of the macrophage population in obese adipose tissue and imply a turnover sufficiently rapid to permit detectable differences after 2-3 weeks of CCR2 antagonism. In contrast to the ability of short-term treatment with a CCR 2 antagonist to improve insulin sensitivity and lower macrophage content in adipose tissue, the effects of a short-term treatment regimen with INCB3344 on proinflammatory adipose tissue gene expression were less consistent. Short-term INCB3344 treatment consistently and significantly lowered Ccr 2 expression by $65 \%(P<0.01 ; n=12)$. However, 

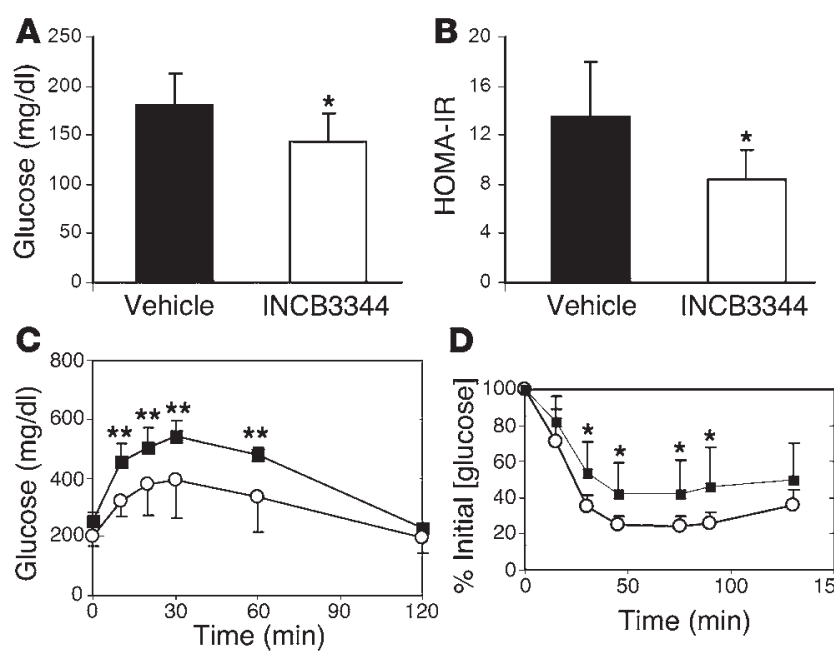

D

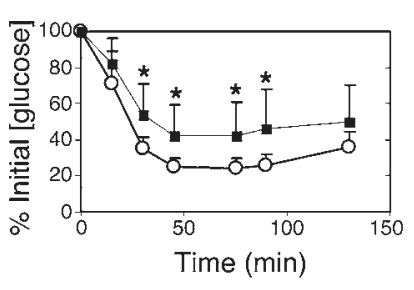

Figure 9

Insulin sensitivity in CCR2 antagonist-treated mice. (A) Hyperglycemia after a daytime fast (6 hours) was reduced in high-fat diet-fed obese mice that received the selective CCR2 antagonist INCB3344 for 14 days (white bars) compared with high-fat diet-fed obese mice that received vehicle injections (black bars; $n=7$ per group; ${ }^{*} P<0.05$ ). (B) Following an overnight fast (14 hours), blood glucose concentrations of INCB3344 and vehicle-treated obese animals were not significantly different. However, fasting insulin concentrations and HOMA-IR values (expressed as IU-mg/dl) were significantly lower in the INCB3344-treated animals $\left(n=7\right.$ per group; $\left.{ }^{*} P<0.05\right)$. (C) Following an intraperitoneal injection of glucose, obese mice treated with INCB3344 (9 days of daily injections; open circles) were significantly less hyperglycemic ( $n=8$ per group; ${ }^{* *} P<0.01$ at $10,20,30$, and 60 minutes) than those treated with vehicle (filled squares). (D) Following an intraperitoneal injection of insulin $(1.5 \mathrm{U} / \mathrm{kg})$ the percentage reduction in blood glucose concentration was greater in obese mice treated with INCB3344 (14 days of daily injections) than in vehicle-treated controls ( $n=7 ;{ }^{*} P<0.05$ at $30,45,75,90$, and 130 minutes). Values are expressed as mean \pm SD.

in contrast, a more modest (20-30\%) reduction in expression of other inflammatory genes, including Tnfa, Csf1r, and Emr1, was not significant in all cohorts tested (data not shown). Similarly, short-term antagonist treatment did not have a measurable effect on hepatomegaly (data not shown). Thus, the development of obesity and the obesity-induced expression of several key inflammatory genes were not reversed with 2 -week antagonism of CCR2.

\section{Discussion}

CCR2 signaling plays pivotal roles in immune responses and atherosclerosis. Its role in metabolic disorders has not been previously appreciated. However, findings presented here demonstrate a complex and important role for CCR2 in both the development and maintenance of obesity and obesity-associated phenotypes. In lean animals, no effect of Ccr2 genotype on metabolic traits could be detected. In contrast, when mice were fed a high-fat diet, $\mathrm{Ccr} 2$ genotype modulated feeding behavior, the development of obesity, and the development of obesity-associated adipose tissue inflammation, ATM accumulation, adiponectin expression, hepatic steatosis, and insulin sensitivity.

Once obesity is established, short-term inhibition of CCR2 signaling with a specific antagonist attenuates obesity-induced macrophage accumulation in adipose tissue and insulin resistance. However, adipose tissue proinflammatory gene expression was not as consistently reduced. The expression of some genes, e.g., $C c r 2$ and $A c d c$, were modulated similarly by genetic deficiency and pharmacological antagonism of CCR2, but others, including the pro-typical inflammatory cytokines, were not consistently decreased in antagonist-treated mice. Similarly, circulating adiponectin and hepatomegaly were not significantly altered by drug treatment. That the effects of the antagonist were more modest than the developmental effects seen with genetic deficiency may reflect a developmental requirement for CCR2 in certain obesity-induced phenotypes and/or relate to the short duration of impaired or absent CCR 2 action.

The requirement for CCR2 in the hyperphagic response to a highfat diet was unexpected. Feeding behavior is integrated and regulated by centers in the central nervous system, in particular, by nuclei within the hypothalamus and brain stem. Populations of neurons, astrocytes, and glial cells express CCR2, and CCL2 binding within the hypothalamus and brain stem have been reported, although possible noninflammatory roles of CCR2 within the central nervous system have not been characterized. Thus, CCR2 may play a role in the ability of feeding centers to respond fully to a highly fat-laden palatable diet. Alternatively, CCR2-dependent regulation of feeding behavior may occur through the action of CCR2 on cells in the periphery, which in turn release molecules that act upon neurons in the central nervous system. Identifying specific hypothalamic and brainstem neuronal and non-neuronal populations that express CCR2, and determining whether central or peripheral INCB3344 can attenuate the development of diet-induced obesity before its onset, will be important initial steps in identifying mechanisms by which CCR2 modulates feeding behavior.

We had hypothesized that ATM content is CCR2 dependent. Indeed, the fraction of ATMs in adipose tissue was $35 \%$ lower in obese $\mathrm{Cr} 2^{-/-}$compared with obese $\mathrm{Crr} 2^{+/+}$mice. The ability of a CCR 2 antagonist to lower ATM content by $25 \%$ in mice with established obesity after 2 weeks of treatment suggests that the effects of genetic deficiency in Ccr2 are not simply attributable to developmental defects in hematopoiesis or chemotaxis. The data also indicate that the turnover of ATMs in obesity is relatively high (half-life in adipose tissue of $\sim 1$ month). Identifying the relevant ligand(s) for CCR2-dependent accumulation of ATMs will require further study, although the expression patterns of CCL2 and CCL7 make them strong candidates. The similarity in adipose tissue expression of CCL2 and CCL7 suggests an additional level of complexity and potential redundancy that will complicate studies. Furthermore, neither pharmacologic modulation nor genetic deficiency of CCR2 normalized ATM content, indicating that factors other than CCR2 participate in macrophage recruitment to adipose tissue.

Recent data suggest that the expression of proinflammatory molecules by adipose tissue is in part due to the expression of these molecules by non-adipocytes, including macrophages (8, $16,25,43-45)$. Ccr2 deficiency attenuates the development of a proinflammatory expression profile by adipose tissue of obese animals, consistent with ATMs being a source of obesity-induced inflammation. However, short-term treatment with a CCR2 antagonist decreased the fraction of macrophages in adipose tissue and improved insulin sensitivity without a similarly broad impact on proinflammatory expression profile in mice with established obesity. This suggests that if the increased production of proin- 
flammatory molecules in obesity were only the result of a quantitative increase in ATM number, then their expression should be uniformly reduced in both the CCR2-deficient and antagonisttreated obese mice. Therefore, the data from obese $\mathrm{Cr} 2^{-/-}$mice suggest that expression of macrophage-derived proinflammatory molecules is also dependent on the maturity or activation state of the ATMs, and not solely on reduction in ATM content per se. Furthermore, differences in reduction in proinflammatory gene expression observed in obese $\mathrm{Ccr} 2^{-/-}$and antagonist-treated mice are likely in part attributable to adipocyte-derived proinflammatory gene expression being differentially affected by complete genetic deficiency and pharmacological antagonism of CCR2.

Adiponectin is an adipocyte-derived hormone that positively regulates insulin sensitivity in liver and muscle. The enhanced insulin sensitivity of $\mathrm{Crr} 2^{-/-}$compared with $\mathrm{Cr} 2^{+/+}$obese mice is consistent with higher expression of adiponectin and higher circulating concentrations of adiponectin observed in obese $\mathrm{Cr} 2^{-/-}$mice. These findings suggest the existence of a CCR2-dependent mechanism for obesity-induced downregulation of adiponectin. Modulation of adiponectin expression may occur indirectly through interactions of adipocytes with CCR2-expressing ATMs and the modulation of obesity-induced inflammatory gene expression. Inflammatory cytokines, including TNF- $\alpha$, are known to downregulate adiponectin expression by adipocytes, and therefore, the lower inflammatory expression profile of adipose tissue from obese $\mathrm{Ccr} 2^{-/-}$mice may contribute to the maintenance of adiponectin expression. Alternatively or in addition, the expression of CCR 2 by adipocytes raises the possibility that $\mathrm{C}$ cr2-dependent downregulation of adiponectin may occur via a direct effect of CCR2 on adipocyte gene expression.

The improved insulin sensitivity of obese $\mathrm{Cr} 2^{-/-}$mice is not entirely attributable to elevated adiponectin expression. Enhanced insulin sensitivity of obese mice treated with a CCR2 antagonist, in which adiponectin expression is similarly elevated but total circulating adiponectin is not significantly different, implicates an additional CCR2-dependent but adiponectin-independent mechanism of insulin resistance. The identity and location of the CCR2-expressing cell(s) required for this effect are not apparent. While the correlation of ATM content with systemic insulin resistance is intriguing, we cannot determine whether ATM content and insulin sensitivity are causally related. Defining the functional relationship between these 2 phenotypes requires development of tools that will permit specific manipulation of ATMs as opposed to other hematopoietic or macrophage populations (e.g., ATMspecific promoter for Cre-based genetic manipulations).

The adiponectin-independent mechanism(s) of CCR2 regulation of insulin sensitivity may occur through direct action on insulin-responsive cell types. The expression and function of CCR 2 in nonhematopoietic cells has not been well characterized. It has been reported that CCR2 is expressed by adipocytes, neurons, endothelial cells, and myocyte precursors. To our knowledge, there is no evidence that mature myocytes or hepatocytes express CCR2. However, we detected increased CCR2 transcript expression in livers of obese mice in the absence of any increase in the number of Kupffer cells (hepatic macrophages) (ref. 8 and S.P. Weisberg and A.W. Ferrante Jr., unpublished observations). Thus, CCR2 in the liver, either in Kupffer cells or nonhematopoietic cells, may modulate the insulin responsiveness of hepatocytes. In contrast, we have not detected any obesity-associated changes in CCR2 expression in whole skeletal muscle.
Here we have shown that CCR2 plays important roles in the pathogenesis of obesity and obesity-associated phenotypes and identify CCR2 as a possible therapeutic target in efforts to treat obesity and its complications.

\section{Methods}

Animals and animal care. $\mathrm{Ccr} 2^{-/-}$were previously generated and have been backcrossed 10 times to the C57BL/6J background (46). C57BL/6J mice used in the INCB3344 studies were obtained from the Jackson Laboratory at 6-8 weeks of age. All mice were housed in Plexiglas ventilated cages (1-3 animals/cage) within a pathogen-free barrier facility that maintained a 12-hour light/12-hour dark cycle. Mice had free access to autoclaved water and irradiated pellet food. In all studies, including studies of Ccr2 genotype effects, and INCB3344 treatment, obesity was induced by a highfat diet that derived approximately $60 \%$ of calories from lipids (D12492; Research Diets Inc.) for 24 weeks beginning at age 6 weeks. Prior to age 6 weeks, mice were fed a standard pellet diet, in which $5 \%$ of calories were provided as fat (PicoLab Rodent 20; LabDiet). Mice on a low-fat diet received the standard chow pellet throughout life.

Mice were sacrificed by $\mathrm{CO}_{2}$ asphyxiation during the second and third hour of the light cycle. Animals were weighed, and adipose tissues (epididymal, subcutaneous, and perirenal) and liver were removed. Tissues analyzed by FACS were processed immediately. Other samples were frozen in liquid nitrogen and stored at $-80^{\circ} \mathrm{C}$ prior to RNA extraction and immunohistochemical analysis.

Mice treated with INCB3344 were lightly anesthetized with inhaled $2 \%$ isoflurane and injected subcutaneously with INCB3344 $(100 \mathrm{mg} / \mathrm{ml})$ emulsified in $10 \%$ carboxymethylcellulose as vehicle. Control animals were similarly anesthetized but subcutaneously injected with vehicle alone. Body composition was determined by dual $\mathrm{x}$-ray absorbance spectroscopy using a PIXImus DEXA scanner specifically designed for mice (Lunar Corp.). Calibration was performed before each set of measurements and data obtained according to manufacturer's protocols. All procedures were approved by Columbia University's Institutional Animal Care and Use Committee.

CCR2 antagonist. INCB3344 was synthesized by the medicinal chemistry department of Incyte Corp. The specificity of this compound for CCR2 and its pharmakinetics of INCB3344 have been described elsewhere (11).

Metabolic testing. Insulin tolerance testing was carried out in animals that were fasted for 6 hours beginning at approximately $10 \mathrm{am}$. After an intraperitoneal bolus injection of recombinant human regular insulin (1.5 $\mathrm{U} / \mathrm{kg}$ ) (Novolin R; Novo Nordisk Inc.), blood glucose concentrations were measured using a Glucometer ELITE XL blood glucose meter (Bayer Corp.) before and 15, 30, 45, 75, 90, and 130 minutes after injection. Glucose tolerance tests were performed after an overnight (14-hour) fast. Blood glucose concentrations were measured before and 15, 30, 45, 60, 90, 120 minutes after an intraperitoneal injection of dextrose dissolved in water $(1 \mathrm{~g} / \mathrm{kg})$.

Microarray gene expression. Total RNA was extracted from the perigonadal (epididymal or parametrial) adipose tissue of individual mice using a commercially available acid-phenol reagent (TRIzol; Invitrogen Inc.). RNA concentration was assessed by absorbance spectroscopy and RNA integrity confirmed by nondenaturing agarose gel electrophoresis. Twenty micrograms of RNA from each sample were further purified from contaminating organics and non-RNA species using a silica resin (RNEasy; QIAGEN) protocol according to the manufacturer's instructions. Total RNA from single animals was individually converted into biotinylated, fragmented cRNA using protocols recommended by the microarray manufacturer (Affymetrix). cRNA samples derived from single animals were hybridized in recommended buffer to microarrays (Affymetrix Murine Genome Array U430 2.0) at $45^{\circ} \mathrm{C}$ for 16 hours. The samples were stained and washed according to the manufacturer's protocol on a Fluidics Station 400 (Affymetrix) and 
scanned on a GeneArray Scanner (Affymetrix). Primary data extraction was performed with Microarray Suite 5.0 (Affymetrix), and signal normalization across samples was carried out using all probe sets with a mean expression value of 500 .

We examined gene expression only for those genes deemed "present" by the Microarray Suite software. To calculate the probability that genes were up- or downregulated in $\mathrm{Ccr} 2^{-/}$compared with wild-type animals, we used Microsoft Excel (Microsoft Corp.) to calculate Student's $t$ test scores for each "present" gene. To identify functionally related groups of genes with similar expression patterns, we analyzed the list of Student's $t$ test scores using Gene Ontology Class Scoring software $(34,47)$.

Immunohistochemistry. Adipose tissue samples were fixed for 12-16 hours at room temperature in zinc-formalin fixative (Anatech Ltd.) and embedded in paraffin. Five-micrometer sections, cut at $50-\mu \mathrm{m}$ intervals, were mounted on charged glass slides, deparaffinized in xylene, and stained for expression of F4/80 as described by Cecchini et al. with an anti-F4/80 monoclonal antibody (CALTAG Laboratories) (48). For each individual mouse tissue block, $15-20$ different $\times 20$ fields from each of 4 different sections were analyzed. The total number of nuclei and the number of nuclei of F4/80-expressing cells were counted for each field using a software algorithm designed for the image analysis software Image-Pro Plus 1.0 (Media Cybernetics Inc.). The fraction of F4/80-expressing cells for each sample was calculated as the sum of the number of nuclei of F4/80 expressing cells divided by the total number of nuclei in sections of a sample. Average adipocyte cross-sectional area was determined for each adipocyte in each field analyzed using image analysis software (SPOT version 3.3; Diagnostic Instruments Inc.).

Isolation of adipose tissue SMCs. Adipose tissue was isolated from mice immediately after $\mathrm{CO}_{2}$ asphyxiation. Tissues were handled using sterile techniques and minced into fine $(<10-\mathrm{mg})$ pieces. Minced samples were placed in HEPES-buffered DMEM (Invitrogen Corp.) supplemented with $10 \mathrm{mg} / \mathrm{ml}$ fatty acid-poor BSA (FAP-BSA; Sigma-Aldrich) and centrifuged at $1000 \mathrm{~g}$ for 10 minutes at room temperature to pellet erythrocytes and other blood cells. An LPS-depleted collagenase cocktail (Liberase 3; Roche Diagnostics Corp.) at a concentration of $0.03 \mathrm{mg} / \mathrm{ml}$ and $50 \mathrm{U} / \mathrm{ml}$ DNAse I (Sigma-Aldrich) were added to the tissue filtrate and the samples incubated at $37^{\circ} \mathrm{C}$ on an orbital shaker $(215 \mathrm{~Hz})$ for $45-60$ minutes. Once digestion was complete, samples were passed through a sterile $250-\mu \mathrm{m}$ nylon mesh (Sefar Inc.). The suspension was centrifuged at $500 \mathrm{~g}$ for 10 minutes. The pelleted cells were collected as the SVCs, and the floating cells were collected as the adipocyte-enriched fraction. The SVCs were resuspended in erythrocyte lysis buffer and incubated at room temperature for 5 minutes. The erythrocyte-depleted SVCs were centrifuged at $500 \mathrm{~g}$ for 5 minutes and the pellet resuspended in FACS buffer (PBS, 0.2\%, FAP-BSA, 5 mM EDTA).

Immunophenotyping and flow cytometry. SVCs isolated from adipose tissue samples were cooled on ice and counted using a hemocytometer. Cell survival rates ranged from $70 \%$ to $90 \%$ as determined by trypan blue exclusion. After counting, cells were centrifuged at $500 \mathrm{~g}$ for 5 minutes and resuspended in FACS buffer at a concentration of $7 \times 10^{6}$ cells $/ \mathrm{ml}$. Cells were incubated in the dark at $4^{\circ} \mathrm{C}$ on a bidirectional shaker for 30 minutes in FcBlock (20 $\mu \mathrm{g} / \mathrm{ml}$; BD Biosciences - Pharmingen), then for an additional 50 minutes with fluorophore-conjugated primary antibodies or isotype control antibodies. Antibodies employed in these studies included: CD11bPE $(2 \mu \mathrm{g} / \mathrm{ml})$ and F4/80-APC ( $5 \mu \mathrm{g} / \mathrm{ml})$ from (CALTAG Laboratories). Following incubation with primary antibodies, $1 \mathrm{ml} \mathrm{FACS}$ buffer was added to the cells. Cells were centrifuged at $500 \mathrm{~g}$ for 5 minutes and resuspended in 1 $\mathrm{ml}$ of FACS buffer. The wash was repeated 2 times. Cells were analyzed on a FACSCalibur and analysis was performed using CellQuest software (BD).

Quantitative real-time PCR. Total RNA was extracted from frozen adipose tissue $(100 \mathrm{mg}$ ) using a commercially available acid-phenol reagent (TRIzol;
Invitrogen Corp.). First-strand cDNA was synthesized using Superscript III reverse transcriptase and random hexamer primers as described in the manufacturer's protocol (Invitrogen Corp.). Samples of cDNA were diluted 1:25 in nuclease-free water (QIAGEN). Samples from each cDNA pool were diluted 1:10, 1:30,1:90, and 1:270 in order to create a standard curve for calculation of relative gene expression levels. PCR amplification mixtures $(20 \mu \mathrm{l})$ contained $10 \mu \mathrm{l} \times 2$ PCR SYBR Green I Quantitect Master Mix (QIAGEN), $0.4 \mu \mathrm{l}$ of $25-\mu \mathrm{M}$ reverse and forward primer mix, and $11.6 \mu \mathrm{l}$ diluted cDNA template. Real-time quantitative PCR was carried out using the DNA Engine Opticon (MJ Research) instruments with the following cycling parameters - polymerase activation: 15 minutes, $95^{\circ} \mathrm{C}$; amplification for 40 cycles: 15 seconds, $94^{\circ} \mathrm{C} ; 20$ seconds, $58^{\circ} \mathrm{C} ; 20$ seconds, $72^{\circ} \mathrm{C}$. After amplification, melting curve analysis was performed as described in the manufacturers' protocol (QIAGEN). Relative expression values were calculated based on the standard curve.

The expression rates of 2 macrophage-specific genes (Emr1, Cd68) that correlated with body mass in our microarray studies, an adipocyte-specific gene $(A c d c)$, lipid metabolism genes (Lipe, Gpam, Fabp4), and proinflammatory genes (Tnfa, Ccr2, Ccl2/Mcp1, Ccl7/Mcp3, Serpine1) were determined by quantitative RT-PCR.

To normalize expression data, we used multiple internal control genes as described by Vandesompele et al. (49). The internal control genes encoding HMG-14 (Hmg14) and ribosomal protein S3 (Rps3) were selected from our murine microarray data set for having high expression and little sample-to-sample variability. For each transcript assayed, intron-spanning primers were designed using publicly available genomic contig sequences obtained through Entrez Gene (http://www.ncbi.nlm. nih.gov/entrez/query.fcgi?db=gene), the public domain primer design software Primer3 (http://frodo.wi.mit.edu/primer3/primer3_code.html), and the DNA analysis software Vector NTI Suite Version 7 (Informax Inc.). Primer sequences were as follows: Rps3 forward, 5'-ATCAGAGAGTTGACCGCAGTTG-3'; Rps3 reverse, 5'-AATGAACCGAAGCACACCATAG-3'; Emr1 forward, 5'-CTTTGGCTATGGGCTTCCAGTC-3'; Emr1 reverse, 5'-GCAAGGAGGACAGAGTTTATCGTG-3'; Cd68 forward, 5'-CTTCCCACAGGCAGCACAG-3'; Cd68 reverse, 5'-AATGATGAGAGGCAGCAAGAGG-3'; Tnfa forward, 5'-CCAGACCCTCACTAGATCA-3'; Tnfa reverse, 5' -CACTTGGTGGTTTGCTACGAC-3'; Acdc forward, 5'-GCTCCTGCTTTGGTCCCTCCAC-3'; Acdc reverse, 5'GCCCTTCAGCTCCTGTCATTCC-3'; Hmg 14 forward, 5'-GCAGAAAATGGAGAGACGGAAAACC-3'; Hmg14 reverse, 5'-AAGGGAGGCGGGACCACTGAC-3'; Ccl2 forward, 5'-AGGTCCCTGTCATGCTTCTGG-3'; Ccl2 reverse, 5'-CTGCTGCTGGTGATCCTCTTG-3'; Pparg forward, 5'GCCCTTTGGTGACTTTATGGAG-3'; Pparg reverse, 5'-GCAGCAGGTTGTCTTGGATG-3'; Lipe forward, 5'-ACGAGCCCTACCTCAAGAACTG3'; Lipe reverse, 5'-ATCTGGCACCCTCACTCCATAG-3'; Fabp4 forward, 5'-AAGAAGTGGGAGTGGGCTTTG-3'; Fabp4 reverse, 5'-CTGTCGTCTGCGGTGATTTC-3'; Serpine1 forward, 5'-TCCTCATCCTGCCTAAGTTCTC-3'; Serpine1 reverse, 5'-GTGCCGCTCTCGTTTACCTC-3'; Gpam forward, 5'-TCCAGAAGGTGAAAAGGAAAGC-3'; Gpam reverse, 5'-GGCAAAAGAGGATGAAGGTGAG-3'.

Protein assays. For the experiments involving INCB3344, insulin levels were determined using an ultrasensitive insulin ELISA (Mercodia AB). In experiments comparing $\mathrm{Crr}^{-/-}$and $\mathrm{Ccr} 2^{+/+}$mice, we performed a multiplexed protein assay for IL-6, MCP1, PAI-1, insulin, and leptin (LincoPlex Mouse Adipokine Panel; Linco Research Inc.). Western blots for adiponectin were performed with $1 \mu \mathrm{l}$ plasma from lean and adiposity-matched obese $\mathrm{Ccr} 2^{-/-}$ and $\mathrm{Ccr}_{2}^{+/+}$mice. Plasma proteins were denatured, reduced, and separated on a $16 \%$ Tris-glycine gel (Invitrogen Corp.) using SDS-PAGE. Proteins were transferred to nitrocellulose (Invitrogen Corp.). We performed immunoblotting for adiponectin and detected the bands using ECL. 
Statistics. Pairwise comparisons of quantitative phenotypes between mice of different genotypes (e.g., obese $\mathrm{Crr} 2^{-/-}$vs. obese $\mathrm{C} c r 2^{+/+}$) or diets (e.g., lean low-fat diet-fed $\mathrm{Cr}_{2}{ }^{+/+}$vs. obese high-fat diet-fed $\mathrm{Ccr} 2^{+/+}$) were assessed by 2 -tailed Student's $t$ test assuming unequal variance. To assess the interaction between genotype and diet for quantitative phenotypes, 2-way ANOVA was performed. Analyses were performed using Prism 3.0 (GraphPad Software Inc.). $P<0.05$ was considered statistically significant.

\section{Acknowledgments}

We thank Philip Scherer for his gift of the anti-adiponectin antibody used for Western analysis. This work was supported by grants from the NIH (DK59960 and DK066525 to A.W. Ferrante Jr.) and the Columbia Diabetes and Endocrinology Research Center (DK063608).

Received for publication December 27, 2004, and accepted in revised form September 12, 2005.

Address correspondence to: Anthony W. Ferrante Jr., Naomi Berrie Diabetes Center, Room 238B, 1150 St. Nicholas Avenue, New York, New York 10032, USA. Phone: (212) 851-5322; Fax: (212) 851-5331; E-mail: awf7@columbia.edu.
1. Berg, A.H., and Scherer, P.E. 2005. Adipose tissue, inflammation, and cardiovascular disease. Circ. Res. 96:939-949.

2. Browning, J.D., and Horton, J.D. 2004. Molecular mediators of hepatic steatosis and liver injury. J. Clin. Invest. 114:147-152. doi:10.1172/JCI200422422.

3. Wellen, K.E., and Hotamisligil, G.S. 2005. Inflammation, stress, and diabetes. J. Clin. Invest. 115:1111-1119. doi:10.1172/JCI200525102.

4. Pickup, J.C. 2004. Inflammation and activated innate immunity in the pathogenesis of type 2 diabetes. Diabetes Care. 27:813-823.

5. Hotamisligil, G.S., Shargill, N.S., and Spiegelman, B.M. 1993. Adipose expression of tumor necrosis factor-alpha: direct role in obesity-linked insulin resistance. Science. 259:87-91.

6. Bastard, J.P., et al. 1999. Evidence for a link between adipose tissue interleukin- 6 content and serum Creactive protein concentrations in obese subjects. Circulation. 99:2221-2222

7. Fried, S.K., Bunkin, D.A., and Greenberg, A.S. 1998. Omental and subcutaneous adipose tissues of obese subjects release interleukin-6: depot difference and regulation by glucocorticoid. J. Clin. Endocrinol. Metab. 83:847-850.

8. Weisberg, S.P., et al. 2003. Obesity is associated with macrophage accumulation in adipose tissue. J. Clin. Invest. 112:1796-1808. doi:10.1172/ JCI200319246.

9. Lin, H.Z., et al. 2000. Metformin reverses fatty liver disease in obese, leptin-deficient mice. Nat. Med. 6:998-1003.

10. Cai, D., et al. 2005. Local and systemic insulin resistance resulting from hepatic activation of IKK-beta and NF-kappaB. Nat. Med. 11:183-190.

11. Brodmerkel, C.M., et al. 2005 Discovery and pharmacological characterization of a novel rodent active CCR2 antagonist, INCB3344. J. Immunol. 175:5370-5378.

12. Skurk, T., and Hauner, H. 2004. Obesity and impaired fibrinolysis: role of adipose production of plasminogen activator inhibitor-1. Int. J. Obes. Relat. Metab. Disord. 28:1357-1364.

13. Hirosumi, J., et al. 2002. A central role for JNK in obesity and insulin resistance. Nature. 420:333-336.

14. Yuan, M., et al. 2001. Reversal of obesity- and dietinduced insulin resistance with salicylates or targeted disruption of Ikkbeta. Science. 293:1673-1677.

15. Arkan, M.C., et al. 2005. IKK-beta links inflammation to obesity-induced insulin resistance. Nat. Med. 11:191-198.

16. Xu, H., et al. 2003. Chronic inflammation in fat plays a crucial role in the development of obesity-related insulin resistance. J. Clin. Invest. 112:1821-1830. doi:10.1172/JCI200319451.

17. Curat, C.A., et al. 2004. From blood monocytes to adipose tissue-resident macrophages: induction of diapedesis by human mature adipocytes. Diabetes. 53:1285-1292.

18. Takahashi, K., et al. 2003. Adiposity elevates plasma MCP-1 levels leading to the increased CD11b-positive monocytes in mice. J. Biol. Chem. 278:46654-46660.

19. Mohanty, P., et al. 2004. Evidence for a potent antiinflammatory effect of rosiglitazone. J. Clin. Endocrinol. Metab. 89:2728-2735.

20. Bruun, J.M., Lihn, A.S., Pedersen, S.B., and Richelsen, B. 2005. Monocyte chemoattractant protein-1 release is higher in visceral than subcutaneous human adipose tissue (AT): implication of macrophages resident in the AT. J. Clin. Endocrinol. Metab. 90:2282-2289.

21. Sartipy, P., and Loskutoff, D.J. 2003. Monocyte chemoattractant protein 1 in obesity and insulin resistance. Proc. Natl. Acad. Sci. U. S. A. 100:7265-7270.

22. Kurihara, T., and Bravo, R. 1996. Cloning and functional expression of mCCR2, a murine receptor for the C-C chemokines JE and FIC. J. Biol. Chem. 271:11603-11607.

23. McQuibban, G.A., et al. 2000. Inflammation dampened by gelatinase A cleavage of monocyte chemoattractant protein-3. Science. 289:1202-1206.

24. Charo, I.F., and Peters, W. 2003. Chemokine receptor 2 (CCR2) in atherosclerosis, infectious diseases, and regulation of T-cell polarization. Microcirculation. 10:259-264.

25. Di Gregorio, G.B., et al. 2005. Expression of CD68 and macrophage chemoattractant protein- 1 genes in human adipose and muscle tissues: association with cytokine expression, insulin resistance, and reduction by pioglitazone. Diabetes. 54:2305-2313.

26. Christiansen, T., Richelsen, B., and Bruun, J.M. 2005. Monocyte chemoattractant protein-1 is produced in isolated adipocytes, associated with adiposity and reduced after weight loss in morbid obese subjects. Int. J. Obes. Relat. Metab. Disord. 29:146-150.

27. Boring, L., et al. 1997. Impaired monocyte migration and reduced type 1 (Th1) cytokine responses in C-C chemokine receptor 2 knockout mice. J. Clin. Invest. 100:2552-2561.

28. Kurihara, T., Warr, G., Loy, J., and Bravo, R. 1997. Defects in macrophage recruitment and host defense in mice lacking the CCR2 chemokine receptor. J. Exp. Med. 186:1757-1762.

29. Nanji, A.A. 2004. Animal models of nonalcoholic fatty liver disease and steatohepatitis. Clin. Liver Dis. 8:559-574, ix.

30. Wellen, K.E., and Hotamisligil, G.S. 2003. Obesity-induced inflammatory changes in adipose tissue. J. Clin. Invest. 112:1785-1788. doi:10.1172/ JCI200320514.

31. Soukas, A., Cohen, P., Socci, N.D., and Friedman, J.M. 2000. Leptin-specific patterns of gene expression in white adipose tissue. Genes Dev. 14:963-980.

32. Nadler, S.T., et al. 2000. The expression of adipogenic genes is decreased in obesity and diabetes mellitus. Proc. Natl. Acad. Sci. U. S. A. 97:11371-11376.

33. Wilson-Fritch, L., et al. 2004. Mitochondrial remodeling in adipose tissue associated with obesity and treatment with rosiglitazone. J. Clin. Invest.
114:1281-1289. doi:10.1172/JCI200421752.

34. Pavlidis, P., Weston, J., Cai, J., and Noble, W.S. 2002. Learning gene functional classifications from multiple data types. J. Comput. Biol. 9:401-411.

35. Statnick, M.A., et al. 2000. Decreased expression of apM1 in omental and subcutaneous adipose tissue of humans with type 2 diabetes. Int. J. Exp. Diabetes Res. 1:81-88.

36. Kern, P.A., Di Gregorio, G.B., Lu, T., Rassouli, N., and Ranganathan, G. 2003. Adiponectin expression from human adipose tissue: relation to obesity, insulin resistance, and tumor necrosis factoralpha expression. Diabetes. 52:1779-1785.

37. Vendrell, J., et al. 2004. Resistin, adiponectin, ghrelin, leptin, and proinflammatory cytokines: relationships in obesity. Obes. Res. 12:962-971.

38. Dandona, P., et al. 1998. Tumor necrosis factoralpha in sera of obese patients: fall with weight loss. J. Clin. Endocrinol. Metab. 83:2907-2910.

39. Lehrke, M., et al. 2004. An inflammatory cascade leading to hyperresistinemia in humans. PLoS Med. 1:e45.

40. Reilly, M.P., et al. 2005. Resistin is an inflammatory marker of atherosclerosis in humans. Circulation. 111:932-939.

41. Ginsberg, H.N. 1991. Lipoprotein physiology in nondiabetic and diabetic states. Relationship to atherogenesis. Diabetes Care. 14:839-855.

42. Ginsberg, H.N. 2000. Insulin resistance and cardiovascular disease. J. Clin. Invest. 106:453-458.

43. Ross, S.E., et al. 2002. Microarray analyses during adipogenesis: understanding the effects of Wnt signaling on adipogenesis and the roles of liver $\mathrm{X}$ receptor alpha in adipocyte metabolism. Mol. Cell. Biol. 22:5989-5999.

44. Fain, J.N., Madan, A.K., Hiler, M.L., Cheema, P., and Bahouth, S.W. 2004. Comparison of the release of adipokines by adipose tissue, adipose tissue matrix, and adipocytes from visceral and subcutaneous abdominal adipose tissues of obese humans. Endocrinology. 145:2273-2282.

45. Fain, J.N., Cheema, P.S., Bahouth, S.W., and Lloyd Hiler, M. 2003. Resistin release by human adipose tissue explants in primary culture. Biochem. Biophys. Res. Commun. 300:674-678.

46. Boring, L., Gosling, J., Cleary, M., and Charo, I.F. 1998. Decreased lesion formation in CCR2-/- mice reveals a role for chemokines in the initiation of atherosclerosis. Nature. 394:894-897.

47. Pavlidis, P., and Noble, W.S. 2001. Analysis of strain and regional variation in gene expression in mouse brain. Genome Biol. 2:research0042.1research0042.15.

48. Cecchini, M.G., et al. 1994. Role of colony stimulating factor- 1 in the establishment and regulation of tissue macrophages during postnatal development of the mouse. Development. 120:1357-1372.

49. Vandesompele, J., et al. 2002. Accurate normalization of real-time quantitative RT-PCR data by geometric averaging of multiple internal control genes. Genome Biol. 3:research0034.1-research0034.11. 